\title{
Effectiveness and safety of serial endoscopic ultrasound-guided celiac plexus block for chronic pancreatitis
}

Authors

Institutions
Michael S. L. Sey ${ }^{1}$, Leslie Schmaltz ${ }^{2}$, Mohammad A. Al-Haddad², John M. DeWitt ${ }^{2}$, Cynthia S. J. Calley $^{3}$, Michelle Juan $^{2}$ Femi Lasisi ${ }^{2}$, Stuart Sherman ${ }^{2}$, Lee McHenry², Thomas F. Imperiale ${ }^{2,4,5}$, Julia K. LeBlanc ${ }^{2}$

Institutions are listed at the end of article. submitted 21. March 2014 accepted after revision 15 . July 2014

\section{Bibliography}

DoI http://dx.doi.org/

10.1055/s-0034-1377919

Published online: 24.10.2014

Endoscopy International Open 2015; 03: E56-E59

(c) Georg Thieme Verlag KG

Stuttgart · New York

E-ISSN 2196-9736

\section{Corresponding author}

Michael Sai Lai Sey, MD

Western University

London Health Sciences Centre-

Victoria Hospital

800 Commissioners Road East

London, Ontario, Canada N6A

5W9

Fax: 1-519-667-6820

msey2@uwo.ca
Background and study aims: Endoscopic ultrasound-guided celiac plexus block (EUS-CPB) is an established treatment for pain in patients with chronic pancreatitis (CP), but the effectiveness and safety of repeated procedures are unknown. Our objective is to report our experience of repeated EUS-CPB procedures within a single patient.

Patients and methods: A prospectively maintained EUS database was retrospectively analyzed to identify patients who had undergone more than one EUS-CPB procedure over a 17-year period. The main outcome measures included number of EUS-CPB procedures for each patient, selfreported pain relief, duration of pain relief, and procedure-related adverse events.

Results: A total of 248 patients underwent more than one EUS-CPB procedure and were included in our study. Patients with known or suspected

\section{Introduction}

$\nabla$

Pain secondary to chronic pancreatitis (CP) is common and difficult to manage. Although opioid analgesics are commonly used, their adverse effects, including sedation, chronic constipation, delirium, nausea, vomiting, narcotic bowel syndrome, respiratory depression, myoclonus, urinary retention, and dependence, negatively impact quality of life [1,2]. Endoscopic ultrasound - guided celiac plexus block (EUS-CPB) is a treatment option for patients with $\mathrm{CP}$ that avoids these adverse events. Approximately $60 \%$ of patients with $\mathrm{CP}$ report relief of pain after EUS-CPB, with a mean duration of 51 days [3]. Because the effect of EUS-CPB is temporary, serial procedures are often required.

At our institution, the rate of major adverse events is less than $1 \%[3,4]$. Minor adverse events may include transient diarrhea $(4 \%-15 \%)$ and postural hypotension (1\%) of up to 48 hours' duration $[5,6]$. The number of endoscopic ultra-
$\mathrm{CP}(\mathrm{N}=248)$ underwent a mean (SD) of 3.1 (1.6) EUS-CPB procedures. In $76 \%$ of the patients with $\mathrm{CP}$, the median (range) duration of the response to the first EUS-CPB procedure was $10(1-54)$ weeks. Lack of pain relief after the initial EUS$\mathrm{CPB}$ was associated with failure of the next EUSCPB (OR 0.17, 95\%CI 0.06-0.54). Older age at first EUS-CPB and pain relief after the first EUS-CPB were significantly associated with pain relief after subsequent blocks ( $P=0.026$ and $P=0.002$, respectively). Adverse events included peri-procedural hypoxia $(n=2)$ and hypotension $(n=1)$ and postprocedural orthostasis $(n=2)$ and diarrhea $(n=4)$. No major adverse events occurred.

Conclusions: Repeated EUS-CPB procedures in a single patient appear to be safe. Response to the first EUS-CPB is associated with response to subsequent blocks.

sound-guided celiac plexus block/neurolysis (EUS-CPB/N) procedures that a single patient can safely undergo has not been reported. Our objective was to report our experience of the safety and efficacy of repeated EUS-CPB/N procedures in a large cohort of patients.

\section{Patients|Materials and methods \\ $\nabla$}

\section{Study design}

The study was conducted at the Indiana University Medical Center, Indianapolis, Indiana, USA. We are a high-volume EUS center staffed by six experienced endosonographers and perform approximately 3000 procedures a year. Our prospectively maintained EUS database was searched for patients who had undergone EUS-CPB over a 17year period (1996-2012). Each medical record was reviewed for the number of EUS-CPB procedures, duration of pain relief, and adverse events. Pain relief was defined as patient self-report of a 
reduction or elimination of pain after the procedure and was treated as a binary variable (yes/no). No further attempt was made to standardize the definition because of the retrospective design of the study. The duration of pain relief was determined by patient report rather than by the interval between procedures. Adverse events were assessed by a telephone call 24 to 48 hours after the procedure, a review of the medical record for emergency department visits or hospital admissions, and patient questioning at the time of the subsequent EUS-CPB. In addition, the following information was abstracted from each medical record: age, gender, indication, and number of EUS criteria for CP. Institutional review board approval was obtained before initiation of the study.

\section{EUS-CPB procedure.}

The EUS-CPB procedure was performed by one of six expert endosonographers according to the standards outlined by the American Society of Gastrointestinal Endoscopy [7]. A radial and/or curvilinear echoendoscope (GF-UM20, GF-UM130, GFUM160, GF-UC140P-AL5; Olympus America, Center Valley, Pennsylvania, USA) was used to evaluate the pancreas for sonographic criteria for CP $[8,9]$. EUS-CPB was performed in patients with established CP ( $\geq 4$ criteria) or suspected CP $(<4$ criteria but with clinical suspicion of CP). A linear echoendoscope (GF-UC140PAL5, GF-UC30P; Olympus America) was used to identify the celiac trunk and celiac ganglia. A fine (22-gauge) aspiration needle (EchoTip; Cook Medical, Winston-Salem, North Carolina, or Expect; Boston Scientific, Natick, Massachusetts) or a 20-gauge celiac plexus needle (ECHO-20-CPN; Cook Medical) was passed through the working channel of the curvilinear echoendoscope. The needle was directed through the gastric wall into the celiac region. If celiac ganglia were identified, they were targeted. If celiac ganglia were not observed, the area lateral or anterior to the celiac trunk was injected with either a unilateral or bilateral approach, according to the endosonographer's preference. Sterile saline was used to "test" proper needle positioning. Suction was applied to the syringe to confirm the absence of blood return. A few milliliters of saline was injected to clear the needle of contaminant from the gastric wall. Once the needle was properly positioned, the EUS technician injected $20 \mathrm{~mL}$ of $0.75 \%$ bupivacaine followed by 40 to $80 \mathrm{mg}$ of triamcinolone (EUS-CPB). The amount of triamcinolone varied according to the endosonographer's discretion. The echoendoscope was then withdrawn, and the patient was observed in the recovery area for approximately 1 hour. After the procedure, all patients received $1 \mathrm{~L}$ of normal saline intravenously and 1 dose of an intravenous antibiotic (ampicillin/sulbactam or ciprofloxacin), followed by a 3-to 5-day course of an oral antibiotic (amoxicillin / clavulanate or ciprofloxacin).

\section{Definitions}

Major adverse events were defined as aspiration, perforation, infection, bleeding or pain that required hospitalization, paralysis or other permanent injury, and death [10]. Minor adverse events were defined as a transient increase in pain, diarrhea, orthostasis, or sedation-associated hypotension or oxygen desaturation. Patients were defined as having established CP if 4 or more EUS features of CP were documented, and suspected pancreatitis if fewer than 4 features were present, but with a clinical suspicion of CP.

\section{Statistical methods}

Descriptive statistics were presented as mean and standard deviation. Nonparametric data were presented as median and range. Generalized estimating equations were used to examine the association between the effectiveness of first EUS-CPB and the effectiveness of subsequent EUS-CPB, the number of EUS features of CP, and the patient's age at first EUS-CPB. Backward elimination was used to determine the final model.

\section{Results}

\section{Study population}

A total of 1108 patients underwent at least one EUS-CPB procedure during the 17-year study period between 1996 and 2012. Of these, 248 patients underwent two or more EUS-CPB procedures, and these made up our study cohort. Effectiveness data were available for 233 patients, but safety data were available for the entire cohort. The mean (SD) age was 43.8 (12.3) years, and 171 patients (69\%) were female. The CP was most commonly idiopathic $($ Table 1$)$.

EUS-CPB was performed in 248 patients with established or suspected $\mathrm{CP}$. The median (range) number of EUS criteria for $\mathrm{CP}$ was $3(0-8)$, and 72 patients had 4 or more EUS criteria for $\mathrm{CP}$. The main pancreatic duct was dilated in 27 patients and a pancreatic stone was seen in 4, of whom 18 underwent endoscopic retrograde cholangiopancreatography (ERCP) drainage without resolution of abdominal pain. The mean (SD) number of EUS-CPB procedures per patient was 3.1 (1.6). The most frequently used medication for EUS-CPB was bupivacaine with triamcinolone (90\%).

\section{Effectiveness of EUS-CPB}

After the first EUS-CPB, 76\% of the patients reported pain relief, and the median (range) duration of pain relief was $10(1-54)$ weeks. Data for the duration of efficacy after each subsequent EUS-CPB are presented in Table 2. Lack of pain relief after the first EUS-CPB was associated with failure to achieve pain relief after subsequent EUS-CPB (OR 0.17, 95\%CI 0.06-0.54) ( $\bullet$ Fig. 1). The number of EUS criteria for CP was not associated with pain

\begin{tabular}{|c|c|}
\hline & $C P(N=248)$ \\
\hline Age, mean (SD) & $43.8(12.3)$ \\
\hline Gender, No. female (\%) & $171(69)$ \\
\hline \multicolumn{2}{|l|}{ Race, No. (\%) } \\
\hline Caucasian & $224(90)$ \\
\hline African American & $22(9)$ \\
\hline Other & $2(1)$ \\
\hline \multicolumn{2}{|l|}{ Etiology of CP, No. (\%) } \\
\hline Idiopathic & $107(43)$ \\
\hline Alcohol & $41(17)$ \\
\hline Other & $14(6)$ \\
\hline Not documented & $86(34)$ \\
\hline \multicolumn{2}{|l|}{ Medications used, No.(\%) } \\
\hline Bupivacaine + triamcinolone & $689(90)$ \\
\hline Bupivacaine & $60(8)$ \\
\hline Other & $18(2)$ \\
\hline \multicolumn{2}{|l|}{ Number of EUS-CPB procedures } \\
\hline Mean (SD) & $3.1(1.6)$ \\
\hline Median (range) & $2.5(2-10)$ \\
\hline
\end{tabular}

CP, chronic pancreatitis; EUS-CPB, endoscopic ultrasound-guided celiac plexus block. 
Table 2 Effectiveness of serial EUS-CPB for chronic pancreatitis over time.

\begin{tabular}{|c|c|c|c|}
\hline $\begin{array}{l}\text { Block } \\
\text { No. }\end{array}$ & $\begin{array}{l}\text { Total No. } \\
\text { with effective- } \\
\text { ness data }\end{array}$ & $\begin{array}{l}\text { No.(\%) } \\
\text { effective }\end{array}$ & $\begin{array}{l}\text { Median (range) } \\
\text { duration of effective- } \\
\text { ness, wk }\end{array}$ \\
\hline 1 & 233 & $177(76.0)$ & $10(1-54)$ \\
\hline 2 & 107 & $84(78.5)$ & $12(2-53)$ \\
\hline 3 & 57 & $49(86.0)$ & $15(2-79)$ \\
\hline 4 & 35 & $35(100.0)$ & $12(2-60)$ \\
\hline 5 & 22 & $22(100.0)$ & $17.5(1-38)$ \\
\hline 6 & 12 & $11(91.7)$ & $12(2-56)$ \\
\hline 7 & 6 & $6(100.0)$ & $23(7-30)$ \\
\hline 8 & 5 & $5(100.0)$ & $12(1-46)$ \\
\hline 9 & 3 & $3(100.0)$ & $20(12-27)$ \\
\hline 10 & 1 & $1(100.0)$ & $17(17-17)$ \\
\hline
\end{tabular}

EUS-CPB, endoscopic ultrasound - guided celiac plexus block.

relief after the first block $(P=0.10)$ ( $\bullet$ Fig.2). Older age at first block $(P=0.026)$ and achieving pain relief after the first block $(P$ $=0.0024$ ) were associated with pain relief after subsequent blocks. For every 10-year increase in age, patients were 1.60 times more likely to obtain pain relief $(95 \% \mathrm{CI} 1.06,2.43)$. Patients who experienced pain relief after the first EUS-CPB were 6.7 times more likely to experience relief after subsequent blocks (95\%CI 2.25-19.72).

\section{Adverse events}

There were 3 minor adverse events that occurred during the procedures (hypotension in 1 patient and hypoxemia to $70 \%$ in 2 patients); these resolved without clinically significant consequences. Transient diarrhea developed in 4 patients, and transient light-headedness occurred in 2 patients following the procedure. No major adverse events occurred during the study period.

\section{Discussion}

Little is known about the number of percutaneous or endoscopic CPB procedures that can be safely performed in a single patient. To our knowledge, this is the first study of the number of EUSCPB procedures performed in a single patient and the associated procedure-related adverse events. Our study contributes several new findings to the EUS literature.

First, our study provides the first report of the long-term safety of repeated EUS-CPB procedures in a single patient. We observed that patients who had CP underwent up to 10 EUS-CPB procedures without serious adverse events. The majority of patients, however, underwent 4 or fewer EUS-CPB procedures. Thus, our findings may not be generalizable to patients who have had more than 4 EUS-CPB procedures. Our study is also not adequately powered to detect rare adverse events $(<1 \%)$, which would require a much larger sample size. Still, given the paucity of large EUS-CPB trials, retrospective studies such as ours provide some evidence about the safety of repeated EUS-CPB.

Overall, EUS-CPB is a relatively safe procedure, and adverse events are infrequent and usually minor. Known and reported adverse events include transient diarrhea (4\%-15\%), transient orthostasis $(1 \%)$, and temporary increase in pain $(9 \%)$ More serious adverse events have been reported, and these include paraplegia, paresthesia, spinal cord infarction, sexual dysfunction, chemical pericarditis, abscess, gastroparesis, gastric necrosis, hemorrhage, perforation, and rarely death [11-22]. These rare ad-
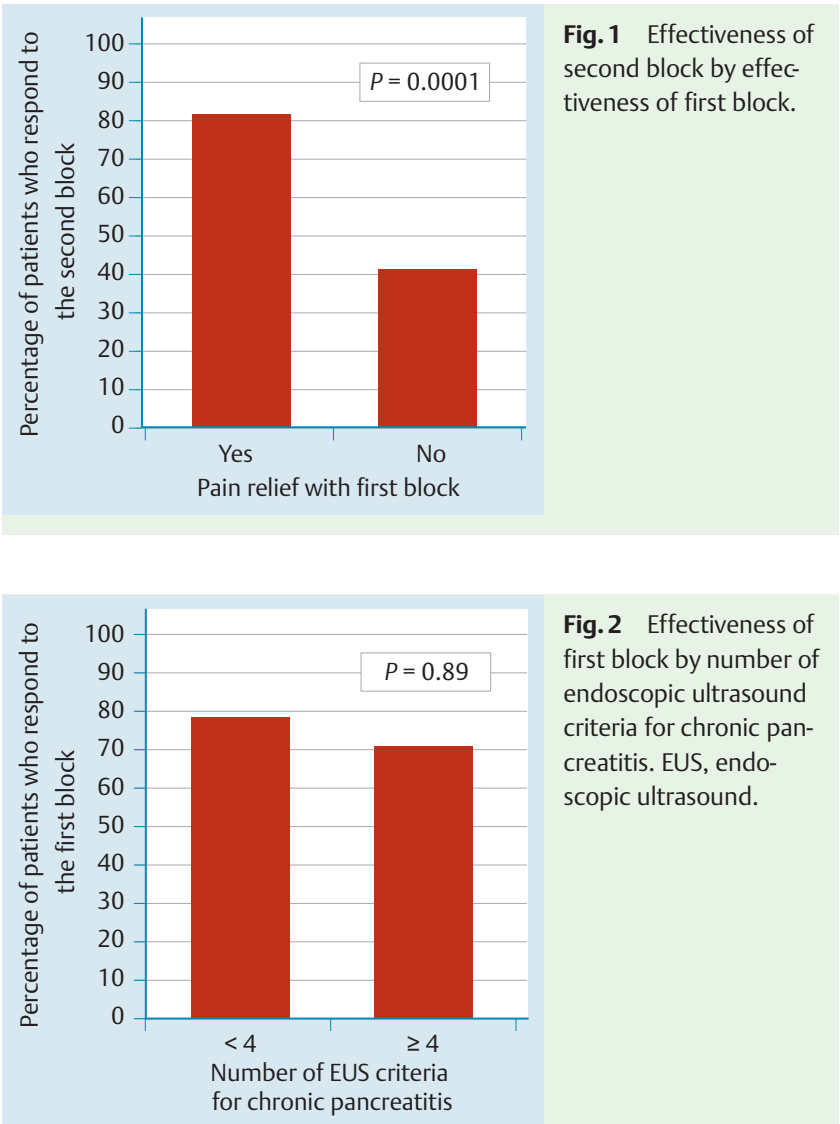

verse events have occurred after both percutaneous and EUSguided blocks and neurolysis. Although unproven, the proximity of the celiac plexus to the tip of the echoendoscope should theoretically result in fewer adverse events.

Secondly, we found that response to the initial EUS-CPB for CP appeared to be predictive of response to subsequent blocks. Alternatively, failure to achieve pain relief after the first EUS-CPB was associated with lack of pain relief after the second block (OR 0.17, $95 \%$ CI $0.06-0.54)$. Although EUS-CPB is generally considered safe, the likelihood of the success of a subsequent procedure should influence the decision to repeat EUS-CPB for CP. This important finding has not been previously reported.

Prior studies of EUS-CPB for CP have reported a response in 50\% to $80 \%$ of patients $[3,5,23,24]$. A meta-analysis of EUS-guided blocks and neurolysis reported response rates of $59 \%$ in $\mathrm{CP}$ and $80 \%$ in pancreatic cancer [25]. These studies, however, reported the response after a single session. In addition, the definition of "pain relief" varied from study to study. Our response rate of $76 \%$ for the initial EUS-CPB for CP is at the higher end of the spectrum but comparable with the rates in the existing literature.

The major limitation of our study is its retrospective design. Treatment response was based on a patient's subjective report of pain reduction or elimination. Further standardization of this definition was not possible because of our retrospective design. However, the willingness of a patient to return for another block and/or the referring physician's opinion that another block would be worthwhile supports the notion that the prior response is clinically meaningful. Other factors influencing the number of EUS-CPB procedures that a patient might undergo were not tracked, such as surgery for pain control and subsequent CPB procedures at an outside institution. We also did not report on the 
effect of direct ganglia injection because this was not done during the first 12 years of the study period, after which direct ganglia injection was done almost exclusively during the last 4 years, after the technique had been described. We did not compare these two groups because many other changes in EUS-CPB developed during this time period that could not be entirely controlled for in an analysis. A selection bias for responders likely existed in our study. It is common in clinical practice for patients who respond to therapy to be more likely to return for another procedure. This may have contributed to our high response rate. With respect to adverse events, it is possible that a major complication might have occurred without our knowledge if the patient was treated at an outside hospital. Given the nature of our tertiary referral center, however, this is unlikely because patients and referring physicians are instructed to contact the EUS physician should an adverse event occur.

\section{Conclusion}

\section{$\nabla$}

Repeated EUS-CPB in the same patient appears to be safe, without major adverse events. Response to the first EUS-CPB for CP appears to be predictive of response to subsequent blocks. A prospective study is warranted to confirm our findings.

\section{Competing interests: None}

\section{Institutions}

${ }^{1}$ Department of Gastroenterology and Hepatology, Western University, London, Ontario, Canada

2 Department of Gastroenterology and Hepatology, Indiana University Medical Center, Indianapolis, Indiana, USA

${ }^{3}$ Department of Biostatistics, Indiana University Medical Center, Indianapolis, Indiana, USA

${ }^{4}$ Regenstrief Institute, Indianapolis, Indiana, USA

${ }^{5}$ Center of Innovation, Roudebush VA Medical Center, Indianapolis, Indiana, USA

\section{References}

1 Eriksen J, Sjogren P, Bruera E et al. Critical issues on opioids in chronic non-cancer pain: an epidemiological study. Pain 2006; 125: 172-179

2 Grunkemeier DM, Cassara JE, Dalton CB et al. The narcotic bowel syndrome: clinical features, pathophysiology, and management. Clin Gastroenterol Hepatol 2007; 5: 1126-1139 (quiz 1-2)

3 LeBlanc JK, DeWitt J, Johnson C et al. A prospective randomized trial of 1 versus 2 injections during EUS-guided celiac plexus block for chronic pancreatitis pain. Gastrointest Endosc 2009; 69: 835-842

4 LeBlanc JK, Al-Haddad M, McHenry L et al. A prospective, randomized study of EUS-guided celiac plexus neurolysis for pancreatic cancer: one injection or two? Gastrointest Endosc 2011; 74: 1300-1307

5 Gress F, Schmitt C, Sherman $S$ et al. Endoscopic ultrasound-guided celiac plexus block for managing abdominal pain associated with chronic pancreatitis: a prospective single center experience. Am J Gastroenterol 2001; 96: 409-416

6 Gress $F$, Schmitt C, Sherman $S$ et al. A prospective randomized comparison of endoscopic ultrasound- and computed tomography-guided celiac plexus block for managing chronic pancreatitis pain. Am J Gastroenterol 1999; 94: 900-905

7 Adler DG, Lichtenstein D, Baron TH et al. The role of endoscopy in patients with chronic pancreatitis. Gastrointest Endosc 2006; 63: $933-$ 937

8 DeWitt J, McGreevy K, LeBlanc J et al. EUS-guided Trucut biopsy of suspected nonfocal chronic pancreatitis. Gastrointest Endosc 2005; 62: $76-84$

9 Sahai AV, Zimmerman M, Aabakken $L$ et al. Prospective assessment of the ability of endoscopic ultrasound to diagnose, exclude, or establish the severity of chronic pancreatitis found by endoscopic retrograde cholangiopancreatography. Gastrointest Endosc 1998; 48: 18-25

10 Adler DG, Jacobson BC, Davila RE et al. ASGE guideline: complications of EUS. Gastrointest Endosc 2005; 61: 8-12

11 Abdalla EK, Schell SR. Paraplegia following intraoperative celiac plexus injection. J Gastrointest Surg 1999; 3: 668-671

12 Sayed I, Elias $M$. Acute chemical pericarditis following celiac plexus block-a case report. Middle East J Anesthesiol 1997; 14: 201 - 206

13 Fujii L, Clain JE, Morris JM et al. Anterior spinal cord infarction with permanent paralysis following endoscopic ultrasound celiac plexus neurolysis. Endoscopy 2012; 44: E265 - E266

14 Gimeno-Garcia AZ, Elwassief A, Paquin SC et al. Fatal complication after endoscopic ultrasound-guided celiac plexus neurolysis. Endoscopy 2012; 44: E267

15 Iftikhar S, Loftus EVJr. Gastroparesis after celiac plexus block. Am J Gastroenterol 1998; 93: 2223-2225

16 Kumar A, Tripathi SS, Dhar D et al. A case of reversible paraparesis following celiac plexus block. Reg Anesth Pain Med 2001; 26: 75- 78

17 Lalueza A, Lopez-Medrano F, del Palacio A et al. Cladosporium macrocarpum brain abscess after endoscopic ultrasound-guided celiac plexus block. Endoscopy 2011; 43: E9-E10

18 Loeve US, Mortensen MB. Lethal necrosis and perforation of the stomach and the aorta after multiple EUS-guided celiac plexus neurolysis procedures in a patient with chronic pancreatitis. Gastrointest Endosc 2013; 77: $151-152$

19 Mittal MK, Rabinstein AA, Wijdicks EF. Pearls \& oy-sters: acute spinal cord infarction following endoscopic ultrasound-guided celiac plexus neurolysis. Neurology 2012; 78: e57-e59

20 Navarro-Martinez J, Montes A, Comps 0 et al. Retroperitoneal abscess after neurolytic celiac plexus block from the anterior approach. Reg Anesth Pain Med 2003; 28: 528-530

21 Pello $S$, Miller A, Ku T et al. Hemorrhagic gastritis and duodenitis following celiac plexus neurolysis. Pain Physician 2009; 12: 1001-1003

22 Shin SK, Kweon TD, Ha SH et al. Ejaculatory failure after unilateral neurolytic celiac plexus block. Korean J Pain 2010; 23: 274-277

23 Levy MJ, Topazian MD, Wiersema MJ et al. Initial evaluation of the efficacy and safety of endoscopic ultrasound-guided direct ganglia neurolysis and block. Am J Gastroenterol 2008; 103: 98-103

24 Sahai AV, Lemelin V, Lam E et al. Central vs. bilateral endoscopic ultrasound-guided celiac plexus block or neurolysis: a comparative study of short-term effectiveness. Am J Gastroenterol 2009; 104: 326 -329

25 Puli SR, Reddy JB, Bechtold ML et al. EUS-guided celiac plexus neurolysis for pain due to chronic pancreatitis or pancreatic cancer pain: a metaanalysis and systematic review. Dig Dis Sci 2009; 54: 2330-2337 